\title{
Influence of smoking and plasma factors on patency of femoropopliteal vein grafts
}

\author{
Sheila Wiseman, Glenda Kenchington, Rachel Dain, Christopher E Marshall, Charles N McCollum,
} Roger M Greenhalgh, Janet T Powell

\begin{abstract}
Objective-To determine the effects of smoking, plasma lipids, lipoproteins, apolipoproteins, and fibrinogen on the patency of saphenous vein femoropopliteal bypass grafts at one year.
\end{abstract}

Design-Prospective study of patients with saphenous vein femoropopliteal bypass grafts entered into a multicentre trial.

Setting-Surgical wards, outpatient clinics, and home visits coordinated by two tertiary referral centres in London and Birmingham.

Patients-157 Patients (mean age 66.6 (SD 8.2) years), 113 with patent grafts and 44 with occluded grafts one year after bypass.

Main outcome measure-Cumulative percentage patency at one year.

Results-Markers for smoking (blood carboxyhaemoglobin concentration $(p<0.05)$ and plasma thiocyanate concentration $(p<0.01)$ and plasma concentrations of fibrinogen $(p<0.001)$ and apolipoproteins AI $(p<0.04)$ and $(a)(p<0.05)$ were significantly higher in patients with occluded grafts. Serum cholesterol concentrations were significantly higher in patients with grafts that remained patent one year after bypass $(p<0.005)$. Analysis of the smoking markers indicated that a quarter of patients $(40)$ were untruthful in their claims to have stopped smoking. Based on smoking markers, patency of grafts in smokers was significantly lower at one year by life table analysis than in non-smokers $(63 \% v 84 \%$, $\mathbf{p}<0.02)$. Patency was significantly higher by life table analysis in patients with a plasma fibrinogen concentration below the median than in those with a concentration above $(90 \% v 57 \%, \mathrm{p}<0.0002)$. Surprisingly, increased plasma low density lipoprotein cholesterol concentration was significantly associated with improved patency at one year $(85 \%)$ at values above the median compared with patency (only 68\%) at values in the lower half of the range $(\mathbf{p}<\mathbf{0 . 0 2})$.

Conclusions-Plasma fibrinogen concentration was the most important variable predicting graft occlusion, followed by smoking markers. A more forceful approach is needed to stop patients smoking; therapeutic measures to improve patency of vein grafts should focus on decreasing plasma fibrinogen concentration rather than serum cholesterol concentration.

\section{Introduction}

Vein bypass operations can dramatically relieve symptoms in patients with critical ischaemia of coronary arteries or distal arteries of the legs. Bypass of a distal artery may prevent a threatened amputation, but even when an autogenous saphenous vein is available the limb is saved in at most $70-80 \%$ of cases. ${ }^{\prime}$
Failure of femoropopliteal bypass in the immediate postoperative period has been attributed to technical problems. ${ }^{2}$ Later failures have been associated with stenosis or thrombosis of the graft, anastomotic intimal hyperplasia, and progression of proximal or distal atherosclerosis. ${ }^{23}$ Interactions between blood and the vessel wall probably contribute to all these processes. Smoking seems to have a dominant role in the causation and progression of peripheral arterial disease, ${ }^{+}$ which, through its adverse effects on endothelium, platelet function, clotting factors, and fibrinolysis, perturbs interactions between blood and vessel walls. Fibrinogen has an essential role in thrombosis, and epidemiological studies have shown it to be an important predictor of cardiovascular disease. ${ }^{56}$ Both total cholesterol and low density lipoprotein cholesterol concentrations are associated with atherosclerotic coronary heart disease, ${ }^{7}$ whereas independently there is an association between low concentrations of high density lipoprotein cholesterol and the disease. ${ }^{8}$ The main apoproteins of these lipoprotein particles may also prove to be useful predictors of coronary heart disease. ${ }^{9}$ These lipids and lipoproteins are also associated with the failure of aortocoronary vein grafts. ${ }^{1011}$

The previous establishment of a multicentre trial of antiplatelet drugs in patients undergoing saphenous vein femoropopliteal bypass provided an independently monitored group of patients in whom blood risk factors associated with atherosclerosis or thrombosis could be studied. We investigated whether objective assessment of smoking and lipid and lipoprotein predictors of atherosclerosis or plasma concentrations of fibrinogen and the fibrin degradation product D dimer, and activity of tissue plasminogen activator inhibitor were associated with the occlusion or failure of femoropopliteal vein bypass grafts.

\section{Patients and methods}

\section{PATIENTS AND CONTROLS}

Blood samples were available from 157 patients, mean age 66.7 (SD 8.2) years, who had entered the multicentre femoropopliteal bypass trial with autogenous saphenous vein bypass. The samples were obtained six months after bypass to determine the patients' postoperative smoking habits. Although 293 patients had entered the trial during this study, blood samples were obtained from 157 unselected patients at clinics where fasting samples could be collected. Preoperative samples and samples at six and 18 months were also obtained from 38 patients entered at the two coordinating centres to establish coefficients of variation within patients. All procedures were approved by local ethical committees. Forty four controls, 38 men and six women, mean age $59 \cdot 2$ (SD 7.6) years, were used to establish normal ranges for special analytes (D dimer, tissue plasminogen activator inhibitor, apo-
Correspondence to: Dr Powell. 
lipoprotein (a)): 21 were current smokers. The controls were patients attending Charing Cross Hospital for repair of a hernia who had undergone non-invasive arterial assessment to exclude important occlusive disease of the legs.': Samples of blood were obtained from patients and controls after overnight fasting, and aliquots of serum and plasma were stored at $-20^{\circ} \mathrm{C}$ until analysis

Patients in the femoropopliteal trial were visited by the trial coordinator every three months during the first year after bypass and every six months thereafter, and the patency of the graft was assessed at each visit. The graft was considered to be patent when a definite pulse could be palpated over the graft with a clearly audible Doppler signal. When the pulse was absent or uncertain, objective tests were used to confirm patency or occlusion (47 patients): the results of digital subtraction angiography, isotope angiography, or duplex scanning were accepted.

\section{LABORATORY METHODS}

Total serum cholesterol and triglyceride concentrations were measured by end point enzymatic methods. Concentrations of the main lipoproteins were measured after preparative salt density gradient ultracentrifugation of plasma using the method of Chung $e$ al. ${ }^{13}$ Apolipoproteins AI, B, and (a) were measured by end point immunonephelometry. The interassay coefficients of variation were: apolipoprotein AI 5\%, apolipoprotein B 6\%, and apolipoprotein (a) 8\% (international laboratory study on the comparability of Apo A-I and Apo B methods, WHO Lipid Reference Centre, Prague). Fibrinogen concentration was measured by an end point immunonephelometric assay; the interassay coefficient of variation was $5 \%$. The assay was intermittently checked against the clot weight; with a paired $t$ test the mean difference between assays was $1 \cdot 12$ (95\% confidence interval $0 \cdot 84$ to $1 \cdot 40)$. Coefficients of variation within patients (preoperative, six month, and 18 month samples) were: cholesterol $6 \%$, triglyceride $16 \%$, apolipoprotein

TABLE I-Characteristics of patients undergoing saphenous vein femoropopliteal bypass. Figures are numbers (percentages)

\begin{tabular}{|c|c|c|c|}
\hline & \multirow[b]{2}{*}{$\begin{array}{l}\text { Main trial } \\
\text { group } \\
(\mathrm{n}=293\end{array}$} & \multicolumn{2}{|c|}{ Study group } \\
\hline & & $\begin{array}{l}\text { With } \\
\text { patent } \\
\text { grafts } \\
(\mathrm{n}=113)\end{array}$ & $\begin{array}{l}\text { With } \\
\text { occluded } \\
\text { grafts } \\
n=44\end{array}$ \\
\hline Mean age (years) & $65 \cdot 8$ & $67 \cdot 0$ & $65 \cdot 5$ \\
\hline Men & $220(75)$ & $79(70)$ & $33(75)$ \\
\hline Women & $73(25)$ & $34(30)$ & $11(25)$ \\
\hline Diabetes & $64(22)$ & $22(19)$ & $7(16)$ \\
\hline \multicolumn{4}{|l|}{ Graft: } \\
\hline In situ & $108(37)$ & $43(38)$ & $16(36)$ \\
\hline Reverse & $185(63)$ & $70(62)$ & $28(64)$ \\
\hline \multicolumn{4}{|l|}{ Anastomosis: } \\
\hline Above knec & $123(42)$ & $46(41)$ & $17(39)$ \\
\hline Below knee & $170(58)$ & $67(59)$ & $27(61)$ \\
\hline Claudication & $107(36)$ & $+1(36)$ & $18(41)$ \\
\hline Rest pain or gangrene & 186,64 & $72(64)$ & $26(59)$ \\
\hline
\end{tabular}

TABLE II-Blood plasma risk factors and patency of 12 month femoropopliteal grafts in 157 patients. Figures are medians (10-90 centiles)

\begin{tabular}{|c|c|c|c|}
\hline . & $\begin{array}{l}\text { Patent grafts } \\
\qquad n=113)\end{array}$ & $\begin{array}{l}\text { Occluded grafts } \\
\qquad(\mathrm{n}=\mathbf{4 4})\end{array}$ & Significance $^{\star}$ \\
\hline Cholesterol $(\mathrm{mmol} / \mathrm{l})$ & $6 \cdot 04(4 \cdot 6-8 \cdot 6)$ & $5 \cdot 30(4 \cdot 5-7 \cdot 1)$ & $p<0.005$ \\
\hline Triglyceride $(\mathrm{mmol} / \mathrm{l})$ & $1 \cdot 90(0 \cdot 98-3 \cdot 86)$ & $1 \cdot 83(0 \cdot 80-3 \cdot 81)$ & NS \\
\hline High density lipoprotein cholesterol $(\mathrm{mmol} / \mathrm{l})$ & $0.92(0.58-1.55)$ & $0.95(0 \cdot 56-1 \cdot 70)$ & NS \\
\hline Low density lipoprotein cholesterol $(\mathrm{mmol} / \mathrm{l})$ & $3 \cdot 30(1 \cdot 83-5 \cdot 0)$ & $2 \cdot 97(2 \cdot 04 \cdot 4 \cdot 14)$ & NS \\
\hline Very low density lipoprotein triglyceride $(\mathrm{mmol} / \mathrm{l})$ & $1 \cdot 30(0 \cdot 52-2 \cdot 81)$ & $1 \cdot 00(0 \cdot 27-2 \cdot 86)$ & NS \\
\hline Carboxyhacmoglobin (") & $1 \cdot 50(0 \cdot 7-3 \cdot 9)$ & $1 \cdot 70(1 \cdot 0-5 \cdot 2$ & $\mathrm{p}<0.05$ \\
\hline Thiocyanate $(\mu \mathrm{mol} / \mathrm{l})$ & $56(30-140)$ & $83(46-190)$ & $\mathrm{p}<0.01$ \\
\hline Apolipoprotein AI (g/I) & $1 \cdot 19(0 \cdot 90-1 \cdot 61)$ & $1 \cdot 23,0 \cdot 91-1 \cdot 76$ & $\mathrm{p}<0 \cdot(04$ \\
\hline Apolipoprotein B $(\mathrm{g} / \mathrm{l})$ & $0.95(0.63-1.28)$ & $0.95(0 \cdot 66-1 \cdot 30$ & NS \\
\hline Apolipoprotein (a)† (mg/l) & $10 \cdot 7(7 \cdot 2 \cdot 12 \cdot 2)$ & $11 \cdot 8(7 \cdot 8 \cdot 13 \cdot 0)$ & $\mathrm{p}<0.05$ \\
\hline Fibrinogen $(\mathrm{g} / \mathrm{l})$ & $3 \cdot 90(2 \cdot 8-5 \cdot 4)$ & $4 \cdot 80(3 \cdot 3-8 \cdot 0)$ & $\mathrm{p}<0.001$ \\
\hline
\end{tabular}

${ }^{\star}$ Mann-Whitnev U test.

$\nmid$ Results obtained from a smaller group of 40 patients with patent grafts and 25 with occluded grafts.

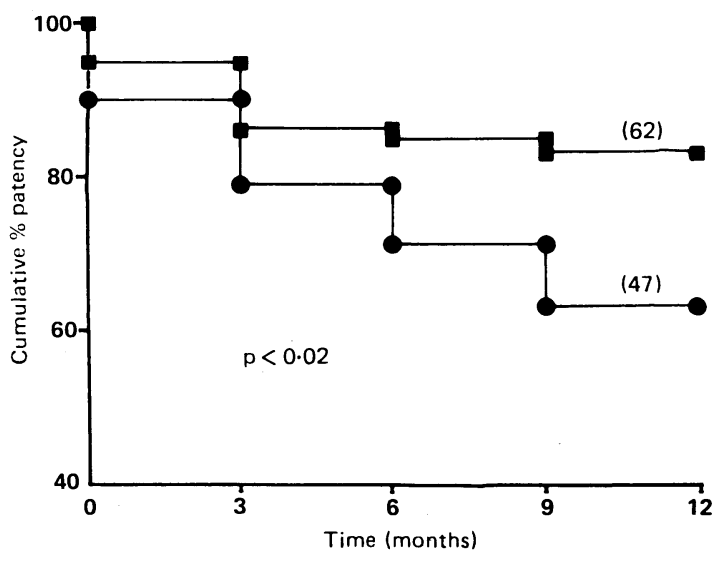

FIG 1-Patency of femoropopliteal vein grafts in smokers (serum thiocyanate concentration $>70$ umol/l (O) and non-smokers (serum thiocyanate concentration $<70 \mu \mathrm{mol} / \mathrm{l})(\mathbf{G})$. Numbers of patients with patent grafts in parentheses

AI $8 \%$, apolipoprotein B $6 \%$, fibrinogen $10 \%$, high density lipoprotein cholesterol $5 \%$, and low density lipoprotein cholesterol $8 \%$. Activity of tissue plasminogen activator inhibitor was measured in plasma containing EDTA by a two stage indirect enzymatic assay (Biopool) based on a method first described by Chmielewska et al. ${ }^{1+}$ The interassay coefficient of variation was $9 \%$. Carboxyhaemoglobin concentrations were determined in whole blood anticoagulated with EDTA with an IL282 carboximeter; concentrations $\geqslant 2 \cdot 0 \%$ indicated continued smoking. ${ }^{15}$ Serum thiocyanate concentrations were determined by an automated colorimetric method; those $\geqslant 70 \mu \mathrm{mol} / \mathrm{l}$ indicated recent smoking. ${ }^{15}$

\section{ANALYSIS}

Individual results were compared by non-parametric Mann-Whitney U tests, life table analysis was used to calculate patency of the grafts, and multivariate discriminant function analysis was carried out on the total data set. ${ }^{16}$ In the life table analysis the $p$ values were obtained from the Lee-Desu statistic. ${ }^{17}$ For individual results data are given as medians (centiles 10-90).

\section{Results}

Two hundred and ninety three patients undergoing autogenous saphenous vein femoropopliteal bypass had entered the femoropopliteal bypass trial by December 1987. The indications for bypass in these patients included disabling claudication, ischaemia at rest, and gangrene. The cumulative patency by life table analysis was $80 \%$ at 12 months and $78 \%$ at 24 months, there being no appreciable difference in patency with indication for operation. ${ }^{18}$ Of the 157 patients in whom suitable blood samples were available, 112 were men and 45 were women. Of the total, 29 were diabetic and 144 had a substantive history of smoking ( $>20$ pack years). They seemed to be representative of the patients entered into the femoropopliteal bypass trial (table I). On direct questioning only 31 of the 157 patients admitted to continued smoking after their bypass. Analysis of smoking markers (serum thiocyanate concentration $\geqslant 70 \mu \mathrm{mol} / \mathrm{l}$ or blood carboxyhaemoglobin concentration $\geqslant 2.0 \%$, or both) suggested that 71 of the 157 patients continued to smoke after bypass grafting, indicating that a quarter of these patients seemed to be untruthful about their smoking habits. Median concentrations of the carboxyhaemoglobin and thiocyanate markers were significantly higher in patients with grafts that had failed (table II). When the patients were divided into two groups, one in which the serum thiocyanate concentration was $<70 \mu \mathrm{mol} / \mathrm{l}$ and the other in which it 
was $>70 \mu \mathrm{mol} / \mathrm{l}$, life table analysis clearly showed significantly improved patency of grafts at one year in the group with the lower thiocyanate concentrations (non-smokers), $84 \%$ having patent grafts compared with only $63 \%$ of smokers $(p<0.02)$ (fig 1 ).

The median serum cholesterol concentration was significantly lower in patients with failed grafts than in those with patent grafts at one year after bypass $(5.30 \mathrm{mmol} / \mathrm{l} v 6.04 \mathrm{mmol} / \mathrm{l}, \mathrm{p}<0.005)$ (table II). Patients with occluded grafts also had a higher median plasma concentration of high density lipoprotein cholesterol and lower concentrations of low density lipoprotein cholesterol (table II), although with their large variance these differences were not significant on univariate analysis. Patients with a low density lipoprotein cholesterol concentration above the median $(3.28 \mathrm{mmol} / \mathrm{l})$ had considerably improved patency of their grafts by life table analysis one year after bypass (85\%) compared with that in patients with a concentration below the median $(85 \% v 68 \%, \mathrm{p}<0.02)$ (fig 2). Patients with occluded grafts also had a higher median concentration of apolipoprotein AI than patients with patent grafts $(1.23 \mathrm{~g} / \mathrm{l} v 1.19 \mathrm{~g} / \mathrm{l}, \mathrm{p}<0.04)$. There was no difference in apolipoprotein $\mathrm{B}$ concentration in the two groups. Plasma apolipoprotein (a) concentration was determined on a range of patients and seemed to be higher in those with occluded grafts (table II).

Median plasma fibrinogen concentration was higher in patients with occluded grafts than in those with patent grafts one year after bypass $(4.80 \mathrm{~g} / \mathrm{l} v 3.90 \mathrm{~g} / \mathrm{l}$, $\mathrm{p}<0.0001$ ), the difference being clearly shown by life table analysis (fig 3): patency at one year was $90 \%$ when the plasma fibrinogen concentration was below the median compared with $57 \%$ in patients with higher concentrations $(p<0 \cdot 0002)$. Two further variables associated with thrombosis were measured, the concentration of $\mathrm{D}$ dimer and activity of tissue plasminogen activator inhibitor. Neither variable was related to patency of the graft at one year, although the median concentration of $\mathrm{D}$ dimer in patients was significantly higher than that in controls $(172(70-440) \mathrm{mg} / \mathrm{l} v$ 65 (24-140) $\mathrm{mg} / \mathrm{l}, \mathrm{p}<0.00001)$.

Discriminant function analysis was used to identify variables predicting failure of the graft. Of the variables listed in table II, plasma fibrinogen concentration followed by the smoking marker thiocyanate concentration were selected as the two most powerful predictors of graft state: together these variables correctly classified $82 \%$ of grafts $(95 / 113$ patent grafts and $34 / 44$ occluded grafts). The addition of low density lipoprotein cholesterol to the analysis improved the number of cases correctly classified to $87 \%$.

Samples of occluded vein grafts were obtained from three patients having a secondary reconstruction from one to six months after femoropopliteal bypass. The vein grafts had a muscular media, a thick intima, and the lumina were occluded by thrombus. There was no evidence of atherosclerosis.

FIG 2-Relation of patency of vein grafts and plasma low density lipoprotein cholesterol concentration. Patients with concentrations $>$ median $(\bullet)$; patients with concentrations $<$ median (ם). Numbers of patients with patent grafts in parentheses

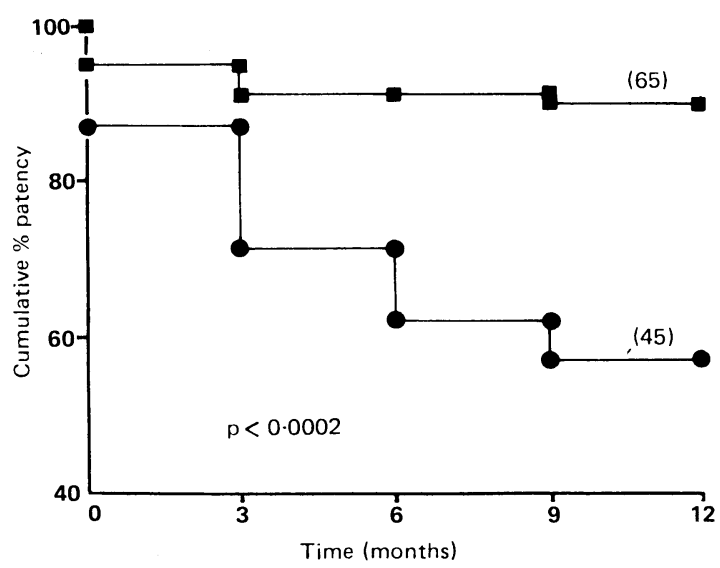

FIG 3-Relation of patency of vein grafts and plasma fibrinogen concentration. Patients with concentrations < median $(\mathbf{\square})$; patients with concentrations $>$ median $(\mathbf{)})$. Numbers of patients with patent grafts in parentheses

\section{Discussion}

The attrition rate of both femoropopliteal and aortocoronary grafts is highest in the first few months after bypass, with $15-20 \%$ of grafts becoming occluded in the first year and only $2-3 \%$ in each subsequent year. ${ }^{18221}$ Whereas angiography is necessary for the surveillance of aortocoronary grafts femoropopliteal grafts may be monitored non-invasively. We have therefore focused attention on factors that might be associated with failure of femoropopliteal grafts in the first year after bypass.

Two principal factors, continued smoking and plasma fibrinogen concentration, adversely affected patency of femoropopliteal vein grafts in this study. In contrast, rather unexpectedly, increased serum cholesterol and plasma low density lipoprotein cholesterol concentrations were associated with improved patency. Further, although vein grafts undergo adaptive changes to the arterial circulation, atherosclerosis within a distal vein graft is conspicuously absent within the first year, when the incidence of graft failure is high."

The influence of smoking on the failure of grafts has received considerable attention, but only a single study, which failed to distinguish vein grafts from prosthetic grafts, used an objective assessment of smoking. ${ }^{23}$ There has been no evidence to associate smoking with failure of vein grafts when information about smoking was obtained by direct questioning. $2+25$ Smoking has been associated with failure of vein grafts when self administered questionnaires were used to determine history of smoking, with only $30 \%$ of femorodistal grafts being patent at two years in smokers compared with $60 \%$ in non-smokers. ${ }^{26}$ Both smoking markers used in our study (carboxyhaemoglobin $t^{1 / 2} 5$ hours, thiocyanate $t^{1 / 2} 6.5$ days) are associated with occasional false positive results, but together they permit identification of covert smokers. Our data indicate that a quarter of the patients were untruthful about their smoking on direct questioning. When these patients were included with current smokers patency of vein grafts in smokers $(63 \%)$ was significantly worse than in non-smokers $(84 \%)$.

Plasma fibrinogen concentration was the most important variable predicting occlusion of grafts, patency in patients with plasma fibrinogen concentrations above the median value being only $57 \%$ compared with $90 \%$ in those with concentrations below the median. Fibrinogen concentration and smoking are not completely independent variables as smoking seems to cause a small increase in plasma fibrinogen concentration. ${ }^{27}{ }^{28}$ Even this small increase may be significantly related to a higher mortality from ischaemic 
heart disease in continuing smokers. ${ }^{2 r}$ Small increases in plasma fibrinogen concentrations related to smoking might also contribute to failure of vein grafts. The turnover of fibrin, as estimated by D dimer concentrations, was greatly increased in all patients undergoing femoropopliteal bypass, but the basal rate of turnover was not greater in patients with occluded grafts. Increased plasma viscosity and a tendency to thrombosis are two possible mechanisms whereby high plasma fibrinogen concentrations could influence occlusion of grafts.

Lipid risk factors associated with accelerated atherosclerosis, increased concentrations of cholesterol, low density lipoprotein cholesterol, and apolipoprotein B with decreased concentrations of high density lipoprotein cholesterol and apolipoprotein AI, were not associated with failure of vein grafts. Cholesterol concentrations were significantly lower and apolipoprotein AI concentrations significantly higher in patients with occluded grafts, whereas life table analysis showed that the incidence of graft failure was higher in patients with lower low density lipoprotein cholesterol concentrations. These lipid variables were not correlated with either plasma fibrinogen concentration or smoking. Plasma apolipoprotein B concentrations were similar in patients with patent and occluded grafts. Apolipoprotein (a), however, which is complexed with apolipoprotein B in defined low density lipoprotein particles, was associated with occlusion of femoropopliteal vein grafts. Apolipoprotein (a) has extensive homology with plasminogen but has no known function in haemostasis or thrombosis and is thought to identify a hereditary component of coronary artery disease. ${ }^{29}{ }^{30}$ Recently, apolipoprotein (a) has been associated with stenosis of aortocoronary vein grafts, ${ }^{31}$ and this apolipoprotein may have a role in arterial thrombosis.

The extensive studies of plasma risk factors and stenosis of aortocoronary vein grafts have been mainly on long term patency in selected groups of patients, those surviving for 10 years after coronary artery bypass $^{10}$ and late survivors who were non-smokers without extensive femoral atherosclerosis, hypertension, or hypertriglyceridaemia." In both these studies of long term survival of grafts increased serum cholesterol and plasma low density lipoprotein cholesterol concentrations were associated with stenosis of vein grafts and a poor prognosis: neither study considered plasma fibrinogen concentration or early failure of the grafts. It will be several years before the association of specific risk factors with late occlusion of femoropopliteal vein grafts can be reported. As the late failure of such grafts has been attributed to progression of proximal or distal atherosclerosis ${ }^{2}$ increased serum cholesterol and plasma low density lipoprotein cholesterol concentrations may prove to be associated with late failure.

Thrombosis is probably of greater importance than atherosclerosis in the early failure of femoropopliteal vein bypass grafts. Continued smoking and increased plasma fibrinogen concentration adversely influence patency indicating that a more persuasive and directed approach to stopping patients smoking is necessary, and this may need to be confirmed by an objective test. Therapeutic intervention to reduce plasma fibrinogen concentration may be a future goal, but therapeutic intervention to reduce serum cholesterol concentration is unlikely to improve salvage of the leg in patients undergoing femorodistal bypass.

We thank all the participants of the femoropopliteal trial, which is supported by the Medical Research Council, for permission to study their patients, Minder Sian for help with the analysis of smoking markers, Dr K McRae for statistical advice, and Jill Wallace for preparing the manuscript. This study was supported by the British Heart Foundation and the Nissan Arterial Disease Research Trust.
The multicentre femoropopliteal bypass trial was coordinated from Charing Cross Hospital, London, by Rachel Dain and from Queen Elizabeth Hospital, Birmingham, by Glenda Kenchington.

Participants in the trial:

London-M Adiseshiah, M Birnstingl, J W P Bradley, A S Chilvers, J Collin, C R R Corbett, J M Edwards, A E B Giddings, R M Greenhalgh, I G Kidson, A O Mansfield, J A P Marston, A R L May, C N McCollum, W M Mee, P J Morris, J A Murie, D Negus, A N Nicolaides, B D Pardy, P H Pattisson, B D Pentlow, M C Pietroni, K P Robinson, J H Scurr, R S Taylor, P C Weaver, J C Williams, and J H N Wolfe.

Birmingham-P R Armistead, F Ashton, E T Bainbridge, W W Barrie, P R F Bell, J M Dolphin, R Downing, J W L Fielding, J F Forrest, D B Hamer, J D Hamer, L J Lawson, J B Marczak, D S Macpherson, M L Obeid, S J A Powis, P N Roberts, G Slaney, and D A K Woodward.

Whittemore AD, Couch NP, Mannick JA. Treatment of arterial occlusive disease of the lower extremities. Annu Rev Med 1985;36:505-14

2 Whittemore AD, Clowes AW, Couch NP, Mannick JA. Secondary femoropopliteal reconstruction. Ann Surg 1981;193:35-42.

3 Szilagyi DE, Elliot JP, Hageman JH, Smith RF, Dall'olmo CA. Biological fate of autologous vein implants as arterial substitutes. Ann Surg 1973;178 $232-46$

4 Hughson WG, Mann JI, Tibbs DV, Woods HF, Walton I. Intermitten claudication: factors determining outcome. Br Med f 1978:i:1377-9.

5 Wilhelmsen L, Svardsudd K, Korsan-Bengsten K, Larsson B, Welin L. Tibblin G. Fibrinogen as a risk factor for stroke and myocardial infarction. N Engl f Med 1984;311:501-5.

6 Meade TW, Brozovic M. Chakrabarti RR, et al. Haemostatic function and ischaemic heart disease. Principal results of the Northwick Park heart tuds: Lancet 1986;ii:533-7.

7 Gordon T, Kannel WB, Castelli W/B, Dawber TR. Lipoproteins, cardiovascular discase and death. The Framingham study. Arch Intern Med 1981;141: $1128-31$

8 Miller NE, Forde OH, Thelle DS, Mjos OD. The Tromso heart study. High density lipoprotein and coronary heart disease: a prospective case control study. Lancet 1977; i:965-8

9 Ball M, Mann JI. Apoproteins: predictors of coronary heart discase? Br Med $\mathcal{J}$ 1986;293:769-70.

10 Campeau L, Enjalbert $M$, Lesperance J, et al. The relation of risk factors to the development of atherosclerosis in saphenous-vein bypass grafts and the progression of disease in the native circulation. N Eingl f Med 1984;311 $1329-32$

11 Blankenhorn DH, Nessim SA, Johnson RL, Sanoarco ME, Azen SP, Cashin Hemphill L. Beneficial effects of combined colestipol-niacin therapy on coronary atherosclerosis and coronary venous bypass grafts. FA.MA 1987; 257:3233-40.

12 Laing SP, Greenhalgh RM. Standard exercise test to assess peripheral arterial disease. Br.Med F 1980;280:13-6

13 Chung BH, W'ilkinson T, Geer JC, Segrest JP. Preparative and quantitative isolation of plasma lipoproteins: rapid, single discontinuous density gradient ultracentrifugation in a vertical rotor. 7 Lipid $R e s$ 1 1980;21:284-91.

14 Chmielewska J, Ranby M, Wiman B. Evidence for a rapid inhibitor to tissue plasminogen activator in plasma. Thromb Res 1983;31:427-36.

5 Russell MAH. Cigarette consumption and biochemical measures of smoke intake. Br.Med f 1982;285:507.

16 Donaldson JD, MacRat KD, Parks T(i. Discriminant function analysis of the carbohvdrate and nitrogen content of gastric secretion in patients wit duodenal ulceration and in control subjects. Ir F Med Sit 1978;147:90-6.

17 Nie NH, Hull CH, Jenkins JG, Steinbrenner K, Bent DH. Statistical package for the social sciences $X$ users' guide. New York: McGraw-Hill, 1983.

$18 \mathrm{McCollum} \mathrm{CN}$. Does platelet inhibitory therapy improve vein bypass patency? In: Greenhalgh RM, Jamieson CW, Nicolaides AN, eds. Limb salvage and In: Greenhalgh RM, Jamieson CW, Nicolardes AN, eds. Limb salzia

19 Harris PL. How TY, Jones DR. Prospective randomised clinical trial to compare in-situ and reversed saphenous grafts for femoro-popliteal bypass. compare in-situ and reves
Brf Surg 1987:74:252-5.

20 FitzGibbon GM, Burton JR, Leach AJ. Coronary by pass graft fate. Circulution 1978:57:1070-4.

21 Fuster VF, Cheesebro JH. Role of platelets and platelet inhibitors in aortocoronary artery vein graft discase. Circulation 1986;73:227-32.

22 Walton $\mathrm{KW}$, Slaney $\mathrm{G}$, Ashton $\mathrm{F}$. Atherosclerosis in vascular grafts for peripheral vascular discase. Atherosclerosis 1985;54:49-64.

23 Greenhalgh RM, Laing SP, Cole PV, Taylor CTW'. Smoking and arterial reconstruction. Br 7 Surg 1981;68:605-7.

24 Green RM, Ouriel K, Ricotta JJ, DeWeese JA. Revision of failed infrainguinal bypass graft: principles of management. Surgery 1986;100:6+6-53.

25 Kretschmer G, W'enzl E, Piza $\mathrm{E}$, $d$ al. The influence of anticoagulant tratment on the probability of function in femoro-popliteal vein bypass surgers: Surgern: 1987:102:+53-9.

26 Myers KA, King RB, Scott DF, Johnson N, Morris PJ. The effect of smoking on the late patency of arterial reconstruction in the legs. Br $\mathcal{F}$ Surg 1978:65:267-71.

27 Meade TW', Iveson J, Stirling Y. Effects of changes in smoking and other characteristics on clotting factors and the risk of ischaemic heart disease. L.ancel 1987;i1:986-8

28 Powell JT, Sian M, Wiseman SA, Greenhalgh RM. Fibrinogen and carbox:hacmoglobin in peripheral arterial discase. Lancet 1988:i:121

29 Brown MS, Goldstein JL. Teaching old dogmas new tricks. Nature' 1987:330: $113-4$

30 Durrington PN, Hunt L, Ishola M, Arrol S. Apolipoprotein (a), Al and B and parental history in men with early onset ischaemic heart disease. Lancet 1988:i:1070-3

31 Hoff HF, Beck GJ, Skihiuski MS, et al. Serum Lpa level as a predictor of vein graft stenosis after coronary artery bypass surgery in patients. Circulatum 1988;77:1238-4t

(Accepted 7 fulv 1989) 